\title{
Stigma in science: the case of earthquake prediction
}

\section{Helene Joffe, Tiziana Rossetto, Caroline Bradley, and Cliodhna O'Connor ${ }^{1}$}

This paper explores how earthquake scientists conceptualise earthquake prediction, particularly given the conviction of six earthquake scientists for manslaughter (subsequently overturned) on 22 October 2012 for having given inappropriate advice to the public prior to the L'Aquila earthquake of 6 April 2009. In the first study of its kind, semi-structured interviews were conducted with 17 earthquake scientists and the transcribed interviews were analysed thematically. The scientists primarily denigrated earthquake prediction, showing strong emotive responses and distancing themselves from earthquake 'prediction' in favour of 'forecasting'. Earthquake prediction was regarded as impossible and harmful. The stigmatisation of the subject is discussed in the light of research on boundary work and stigma in science. The evaluation reveals how mitigation becomes the more favoured endeavour, creating a normative environment that disadvantages those who continue to pursue earthquake prediction research. Recommendations are made for communication with the public on earthquake risk, with a focus on how scientists portray uncertainty.

Keywords: boundary work, earthquake prediction, social representations, stigma in science

\section{Introduction}

In the last week of March 2009, an Italian laboratory technician announced that instruments he had built to measure radon patterns indicated that a major earthquake was imminent near the town of L'Aquila in the Abruzzo region of central Italy. The area had experienced a number of minor seismic events in the preceding months and the warning was publicised extensively, provoking widespread alarm (Fountain, 2OII). Local authorities denounced the technician for causing unnecessary panic, and he was issued with an injunction forbidding him from publicly communicating further earthquake predictions. In response to public concern, a meeting of the National Commission for the Forecast and Prevention of Major Risks was convened on 3I March 2009 to assess the risks posed to the Abruzzo region. It concluded that evidence for the laboratory technician's prediction was weak and that a major earthquake was unlikely, although the possibility could not be excluded (Nosengo, 20IO). At a subsequent press conference the public was reassured that recent tremors were normal for a seismic area and did not signal an increased risk of a major earthquake, with one official reportedly suggesting that citizens need only relax with a glass of wine (Hall, 20I I). The following week, a 5.8-magnitude earthquake befell L'Aquila, claiming the lives of 309 people.

Local residents claimed that the communications that followed the meeting on 3I March lulled citizens into a false sense of security, persuading many that evacuating 
their homes when the initial tremors began was unnecessary and thereby causing avoidable deaths (Nosengo, 20I0). This view was shared by public prosecutors, who charged and successfully convicted seven members (six scientists and one government official) of the scientific panel of manslaughter. The scientific community responded to the verdict with outrage and the scientists' defence teams launched a process to contest the decision. As a result, the six-year sentences handed down to the scientists (three seismologists, two seismic engineers, and one volcanologist) were overturned on appeal on Io November 20I4 and they were acquitted definitively of any offence on 20 November 2015 (Cartlidge, 20I5). The sole conviction upheld was that of the public official, who was judged guilty of 'negligence and imprudence' in making statements that falsely reassured the public that a major earthquake was unlikely (Cartlidge, 2015).

At the heart of this sequence of events lies a mismatch between public and scientific conceptualisations of earthquake prediction. This mismatch warrants investigation because of the consequences it has for the communication of seismic risk information. This paper casts light on one side of the equation: the position that earthquake prediction occupies within contemporary seismology, as revealed through interviews with earthquake scientists. The analysis contextualises earthquake scientists' contributions to risk assessment and communication by revealing the conceptual frameworks that guide their approach. In doing so it provides a glimpse into how emotional and social processes can shape the construction of scientific consensus by establishing certain scientific topics as 'taboo' among scientists.

\section{The rise and fall of earthquake prediction}

When the modern field of seismology began to emerge in the late nineteenth century, accurate prediction of forthcoming earthquakes was an important guiding objective. Early seismologists perceived prediction as the logical aim of earthquake study, and there was evident public enthusiasm for this goal (Milne, I9I I). Optimism about the prospect of predicting earthquakes persisted throughout much of the twentieth century (Brace, I975; Press, I975; Geller et al., I997). With funding flooding into seismology in an effort to push prediction research to its conclusion, and news of an apparently successful (although subsequently discredited) prediction attempt in China, the development of a reliable means of predicting earthquakes seemed imminent (Hough, 2009).

Following several high-profile unsuccessful prediction attempts and the failure of sustained research to indicate any consistent precursors of seismic activity, however, a backlash against earthquake prediction began to germinate (Allen, I982; Hough, 2009). In the I970s and I980s, as mainstream seismology shifted its attention to issues of resilience and probabilistic hazard assessment, earthquake prediction was gradually pushed beyond the boundaries of legitimate scientific inquiry (Geller et al., I997; Sarewitz, 2010). The newly discredited status of prediction was exemplified in a speech made by Charles F. Richter on accepting the I976 Harry Fielding Reid 
Medal of the Seismological Society of America, wherein the metaphorical grandfather of seismology said of earthquake prediction:

Since my first attachment to seismology, I have had a horror of predictions and of predictors. Journalists and the general public rush to any suggestion of earthquake prediction like hogs toward a full trough. It is a parallel to the obsession with a cure for cancer, or with the question of life on other worlds. There is nothing wrong with aiming toward prediction, if that is done with common sense, proper use of correct information, and an understanding of the inherent difficulties. Otherwise, the subject provides a happy hunting ground for amateurs, cranks, and outright publicity-seeking fakers. The vaporings of such people are from time to time seized upon by the news media, who then encroach on the time of men who are occupied in serious research (Howell and Richter, I977, p. I246).

Despite mainstream science's current disillusionment with earthquake prediction, instances of prediction continue to surface intermittently, by soothsayers or 'maverick' scientists. Such cases can preoccupy the media and the public, particularly in seismically-active regions. Alongside the L'Aquila example, another instance of earthquake prediction occurred in Rome, Italy, where the rediscovery of a decades-old earthquake prophecy provoked workplace absentee levels as high as 20 per cent on I I May 20I I (BBC, 20II). Meanwhile, in Christchurch, New Zealand, a claim that lunar cycles indicated a major earthquake in March 20I I reportedly led some residents to leave the city (Booker, 20II). Empirical studies of public responses to such predictions reveal that a significant proportion of the population believes them: in the context of the United States, Turner, Nigg, and Paz (1986) and Major (I998) reported levels of belief in earthquake predictability as high as $60-85$ per cent, although Farley (1998) documented a lower figure of 20-35 per cent. Moreover, the press covers instances of earthquake prediction extensively (Nigg, I982; Dearing and Kazmierczak, I993; Shipman, Fowler, and Shain, I993; Dearing, I995). Consequently, there is a tension between scientific dismissal of earthquake prediction and public interest in and demand for it. Earthquake prediction maintains its presence on the societal agenda despite not being a major focus of scientific investigation.

\section{Boundary work and stigma in scientific inquiry}

The vocabulary chosen by Richter in the above quote is salient in that its tone is highly emotive: 'horror of predictions' and 'hogs toward a full trough'. This is far removed from an idealised picture of scientific thought as restrained, circumspect, and wholly rational. Decades of social psychological research have shown that the knowledge produced by social groups is subject to the dynamic interplay of cultural assumptions, emotion, and social influence. History and philosophy of science studies demonstrate that such dynamics also shape the construction of scientific knowledge (Kuhn, I962; Feyerabend; I975; Barnes, Bloor, and Henry, I996). The case of 
earthquake prediction offers a valuable opportunity to discern how scientific consensus is not only built on the accumulation of empirical information but also on emotional and social processes.

It seems self-evident that scientists experience emotion while conducting their research: dejection, enthusiasm, frustration, and inspiration are common characteristics of cultural narratives of the scientific process. Historical and anthropological research underlines the importance of affective rewards, such as awe or excitement, in motivating and sustaining scientific labour (Brown, I996; Fiege, 2007). Holton (I996) attributes the emotional valence of scientific activity to a finding's correspondence with a scientist's 'thematic presuppositions': implicit, emotionally-infused convictions about nature and the world. These tacit commitments to certain kinds of concepts, methods, evidence, and solutions both motivate and constrain the selection of and the approach to scientific topics (Merton, I975). Holton (I996) argues that these presuppositions are not merely individual idiosyncrasies; rather, most are widely shared among groups of scientists. Yet, the social nature of scientists' convictions and attendant emotional experiences-how they develop and are collectively maintained within scientific communities-remains under-theorised.

An exception to this is the work of Ramsden (2009), who employs the concept of stigma to analyse how scientific fields deal with the legacy of historical scientific activity that is later judged to be pernicious. Stigma, a concept developed by sociologist Erving Goffman (I963), denotes a 'spoiled identity' that is socially ascribed to a person, group, or thing. Ramsden (2009, p. 854) suggests that stigma is a central process guiding the development of science, whereby particular theories, paradigms, or scientists are relegated because they are 'deemed less than truthful, even dangerous and immoral'. As an example, Ramsden (2009) illustrates how in the period following the Second World War , 'eugenics' became regarded as a 'dirty word' (Kevles, I985) from which mainstream geneticists explicitly distanced themselves. The renaming of the 'American Eugenics Society' as the 'Society for the Study of Social Biology' is a case in point; applying the term 'eugenics' to discredit opponents' work is another.

These are examples of 'boundary work', which is an important feature of the operation of stigmatisation within science. Gieryn (I983) asserts that scientists implement rhetorical strategies to demarcate clearly their own work from symbolically contaminated intellectual activities. Boundaries between the scientifically legitimate and illegitimate are carefully policed by the scientific community, and are central in how different disciplines or research programmes compete for esteem and resources. Scientists who invalidate opposing perspectives and stress their distance from their rivals by associating them with quackery and pseudoscience are engaging in 'boundary work'. This has many instantiations with less extreme implications than eugenics, such as the denunciation of the continental drift theory of Alfred Wegener (I929) the hypothesis that the continents once formed a single landmass, before breaking apart and drifting to their present locations. First conceptualised in the early twentieth 
century, it was derided for decades and regarded as highly unscientific, yet now lies at the basis of plate tectonics, a widely accepted theory.

The present study sought to explore the role played by emotional and social processes in scientific knowledge by concentrating on the highly contested area of earthquake prediction. The focus was on the views that earthquake scientists espoused in semi-structured interviews with I7 participants in 20I2. This is the first study to examine boundary work, emotion, and stigma in science by gauging the scientists' own representations systematically, as revealed in their verbal dialogue. It sought to answer the following questions:

- How is earthquake prediction represented by earthquake scientists?

- Is it a case of stigmatising boundary work?

- What are the implications for risk communication and management?

\section{Methodology}

\section{Participants}

The populations of interest for this study were earthquake geologists and seismologists. The inclusion criteria were that participants possessed a seismology-related doctorate and worked in a university, public research facility, or seismology-related industry, such as insurance. For pragmatic reasons relating to access and arranging interviews, the evaluation centred on scientists based in the United Kingdom. An extensive internet search was conducted to identify potential participants, with terms such as 'British seismologist', 'UK seismology', and 'registered seismologist' entered into search engines. The webpages of universities offering taught courses in seismology were also examined to identify relevant staff members. Those whose online profiles specifically mentioned working as a seismologist or conducting earthquakerelated research were contacted by email or telephone and invited to participate in a social scientific study exploring seismologists' thoughts on earthquake science. Snowball sampling methods were employed too, whereby the researchers asked participants for suggestions of other individuals who fulfilled the criteria and might be interested in taking part.

In total, 24 potential interviewees were invited to participate, of whom I7 agreed. Of these, two were female and Is were male. Fourteen participants were British, with three originating from other countries. Sixteen were working in the UK at the time of the study, with one based in another European country. Eleven were university-based lecturers/researchers, five worked for public research bodies, and one worked in the insurance industry. Participants defined their disciplinary identity in a variety of ways, including 'active tectonics', 'civil engineer specialising in earthquake hazard', 'earth scientist', 'engineering seismologist', 'geologist', 'geophysicist', and 'seismologist'. Most had worked in and/or studied highly seismic areas of the world. 


\section{Interview procedure}

Data were collected using semi-structured, in-depth interviews (Wilkinson, Joffe, and Yardley, 2004). An interview schedule was developed and participants were asked about:

- their fields of research;

- how prediction features in their field;

- how they define earthquake prediction;

- their feelings about traditional or mythical ideas surrounding earthquake prediction;

- their impression of how the public views earthquake prediction;

- their experience of communicating research to the wider public; and

- whether they see earthquake prediction as a future possibility.

Interviewers encouraged participants to expand on their answers through prompts such as 'could you tell me more about that?' or 'how do you think/feel about that?'. An initial pilot interview was conducted and interview techniques were refined on this basis.

Interviews were conducted by two researchers with a background in psychology, who were trained to ensure consistency in procedures, and took place at locations convenient for participants (usually at their workplace) between April and July 20 I 2. At this time, the L'Aquila trial was ongoing but a verdict had not yet been reached. One participant was interviewed via telephone owing to distance. Interviews lasted between 22 and 6I minutes, with an average duration of 4I minutes. All of them were audio recorded and subsequently transcribed and imported into the ATLAS.ti data analysis software package (Friese, 20I4).

\section{Thematic analysis}

The interview data underwent a thematic analysis, a qualitative technique to pinpoint the most prevalent patterns of meaning in a dataset (Boyatzis, I998; Joffe, 2012). Thematic analysis involves coding or categorising interview transcripts according to a coding frame devised by the researchers to reflect the content of the interviews.

The coding frame was developed by initially reading through the transcripts to identify inductively recurring ideas, which were entered as codes. To assess the reliability of the coding frame, two independent coders used it to code four randomly chosen interviews. These two coded datasets were compared to evaluate consistency between coders, and the coding frame was refined on this basis. An additional four interviews were then double-coded using the revised coding frame and coding patterns were compared using Cohen's kappa analyses. The average inter-coder reliability was 0.7I, indicating 'substantial' agreement (Landis and Koch, I977).

Once all of the interviews were coded, a frequency table was generated to establish the codes that were most prevalent in the data (that is, the proportion of interviews in which they appeared). This allowed the researchers to observe the patterns of meaning present throughout the dataset, rather than in only small numbers of interviews. Codes that related to similar issues were grouped together to form key themes that characterised the content of the interviews. 


\section{Results}

Three themes were extracted from the dataset, revealing a relatively consensual representation of earthquake prediction as (i) impossible, (ii) harmful, and (iii) stigmatised. The first two themes illuminate how scientists appraise the empirical status and practical effects of earthquake prediction, and show how scientists position their own perspective in opposition to what they see as misguided viewpoints of the public and of certain colleagues. The third theme highlights how the discredited position of prediction within seismology is sustained not only by its empirical failure, but also by a symbolic 'taint' that has developed around the topic of prediction and those who tout it.

\section{Prediction is impossible}

The most dominant facet of participants' representations of earthquake prediction was that prediction is impossible. An explicit statement that prediction is not scientifically possible was expressed in the vast majority of interviews, and was usually the immediate response when the topic was raised:

earthquake prediction means saying there will be an earthquake next Wednesday at 9.30 at this particular place of this particular size, right? And we are nowhere near being able to do that $[7] .^{2}$

In explaining the unfeasible nature of prediction, most participants found it important to differentiate between the terms 'prediction' and 'forecasting'. Participants universally interpreted the term 'prediction' as denoting statements about future seismic events that had very high degrees of certainty and spatial and temporal specificity. In contrast, 'forecasting' was taken to refer to the production of statements about the future that are probabilistic in nature and incorporate long time spans. On several occasions when the interviewer mentioned the term 'prediction', participants corrected her and steered the discussion towards the vocabulary of forecasting. Generally, forecasting was seen as a scientifically valid pursuit whereas prediction was dismissed as a 'fool's errand':

prediction is a waste of time. Forecasting, when we say what the event rate is in say 100 years for a particular city and say what the maximum magnitude is, that's useful. That gives people time to sort out their building [10].

For this sample, two main factors underpinned the impossibility of earthquake prediction. First, all bar two participants attributed the inability to predict earthquakes to the limits of current knowledge, data, and/or tools. They stated that contemporary techniques are insufficiently sensitive to allow for precise modelling of future earthquake occurrences:

with the tools we have at the moment and the analytical capabilities, I don't believe we are in a position to go for predictions [15]. 
The second factor contributing to the impossibility of earthquake prediction related to features of the geological system itself. The majority of participants described the physical system from which earthquakes result as complex, chaotic, or non-linear. In their eyes, these properties make the system intrinsically resistant to prediction, which necessarily relies on linear causal logic:

it's impossible to have sufficient information to predict this phenomena because it's so chaotic or it's a very high non-linear chaotic system and unless you know everything perfectly then your prediction deterministic framework won't work [13].

Participants volunteered a largely consensual historical narrative of how this orientation towards prediction had developed, describing how early optimism about the prospect of prediction soured as research proved fruitless. The rejection of prediction was thereby portrayed as a logical, rational process: the field abandoned the pursuit of prediction because research failed to produce useful results. As one participant noted:

Back in the 1950s-1960s, it was routinely expected that in the next 50 years earthquake prediction would be a matter of routine. Well here we are, and we don't have a working earthquake prediction system at all. And there are quite a lot of seismologists who are coming round to the opinion that we never will. That earthquakes are so essentially a chaotic phenomenon that there's never going to be a way of actually predicting them with any sort of reliability [3].

Although representations of prediction as impossible dominated the data, they were not monolithic. Approximately one-third of participants made statements implying that prediction was a possibility. For most of these, prediction was a theoretical rather than a concrete possibility: they were simply reluctant to rule out the possibility of a major advance in knowledge that would eventually facilitate accurate short-term prediction. As one participant stated:

I think that it's always possible that someone will come up with a great idea that nobody's ever thought of -we've cracked the problem. But as I say, people have been trying hard for 50-6o years and not come close to finding a workable system [9].

Only one interviewee described earthquake prediction as a strong immediate prospect. This participant was very aware of occupying a minority position and discussed at length the difficulties experienced when sharing these ideas with colleagues:

The effects are known, I believe that the effects are really quite well proved, it's just that people do not like fundamental new ideas [12].

Thus, despite a small dissenting minority, the data revealed a strong consensus that earthquake prediction is not a feasible scientific aim. The scientists felt, though, that 
laypeople were insufficiently appreciative of the impracticality of prediction. The sample believed that lay publics maintained a strong interest in earthquake prediction, and reported that the topic arose frequently in their contact with members of the public. They felt that this public enthusiasm for prediction jeopardised their field's reputation, because the lack of progress towards prediction was interpreted as a failure of science:

Well I think the public want you to predict date, time, magnitude. Because that's what they want, and a lot of people, well a lot of the public will actually say to me well why are you spending all this money monitoring earthquakes when you can't even predict them. Why not? [4].

I think people perhaps, there is almost a sense of disappointment though, like oh I thought you scientists were doing better [6].

In several interviews the seismological scientists delineated scientists and laypeople as distinct populations who think in qualitatively different ways and have appreciably different priorities. This was represented as a barrier to communication, because scientific information was seen to require translation into a different register to be comprehensible to the public. In particular, laypeople were seen to have specific difficulty in managing issues of complexity, probability, and uncertainty:

I think we'll always be dealing with probabilities, just in the same way as people forecast the weather, no it's not a prediction, the public understands prediction to be something a lot more precise. Often scientists use a prediction meaning 'here's my model, this is what it predicts within these uncertainty bounds' but the public thinks prediction is more deterministic so you have to be careful [11].

You could do some excellent research using the most sophisticated models and resources that are on the planet but all people want are pretty pictures and nice videos and it's very, very difficult and it's a huge amount of work for an academic than most type of research [sic] to convert the research into something that people would care about [13].

The 'problem' of getting through to the public was seen as solvable through education. On the whole, participants viewed public engagement as synonymous with public education. The science-society tensions in relation to earthquake prediction would be remedied, according to these scientists, by correcting the public's factual misunderstandings and misaligned priorities:

But what we can't do is oh in 10 minutes or next week or next month there is going to be an earthquake so my feeling about it is we should get away answering of that nature and what that involves doing is making sure that local populations and the media don't ask those questions, and the way to do that is to educate them about what we do know and what we can't possibly answer. So in the future I would like to see a situation where people like me, seismologists, have educated the at-risk people to ask the right questions [5]. 
The data revealed, therefore, strong conviction within science concerning the impossibility of earthquake prediction, and frustration that the general population failed to grasp this scientific principle.

\section{Prediction is harmful}

The second theme captures how resistance to prediction was premised not only on its presumed impossibility, but also, in the minds of many participants, as actively harmful. The ramifications of earthquake prediction for society were discussed extensively in the interviews. On some occasions the development of a reliable earthquake prediction mechanism was framed as a positive prospect, because it would facilitate preparation and evacuation. Prediction was frequently described as a 'holy grail' or 'silver bullet', implying that it is a notionally positive thing, albeit something of a folly or an unrealisable aim. Reference to the beneficial elements of prediction, though, was often followed immediately by a 'but' clause in which participants redirected discussion to the more salient, from their perspective, question of its potential harm.

The harmful consequence that most preoccupied interviewees was the belief that a focus on prediction distracts attention from creating resilient structures, which participants saw as the more pressing objective. The vast majority of participants explicitly stated that resilience was more important than prediction:

What I'd like to see is in 100 years' time is a situation where we don't have to bother trying to predict earthquakes anymore because all the building stock is sorted. It's obvious isn't it? So I think earthquake prediction will die out hopefully, in the next 100 or so years because it's utterly useless [5].

Approximately one-half of the participants also expressed concern that instances of prediction would provoke unnecessary public panic or distress. Public panic was seen as injurious to earthquake preparation, undermining the likelihood of 'rational' behaviour, driving people into hazardous outdoor spaces, and disrupting infrastructure networks and social order:

If you were to go onto public radio in Los Angeles and say there is an earthquake predicted, a magnitude 7.5 earthquake is going to happen tomorrow morning, the chaos that would ensue if people believed it, in terms of panicking, stampeding, looting, car crashes and unoccupied buildings, the chaos that could ensue could be tremendous [6].

Numerous participants also mentioned the danger of 'false alarms', in terms of damaging the field's credibility and undermining people's willingness to respond to genuine threats in the future:

you get into that 'the boy who cried wolf' sort of syndrome where people think, oh this guy's an idiot, these people are idiots who don't know what they're talking about so next 
time you say there's going to be an earthquake in three days, the chances of them actually adhering or paying any attention to that is going to decrease all the time [14].

The potentially harmful ramifications of incorrect risk communications 'raised the stakes' for scientists' contributions to public dialogue on risk. In general, because scientists were acutely aware of the real-world repercussions of their work, they took very seriously the obligation to ensure that their public communications were socially responsible:

Because once you've delivered information to the public then that becomes a really serious issue because that has to be taken on board with emergency planning departments and the government. They have to put in place something to evacuate the people [4].

Several participants, in discussing the practical consequences of their public engagement, emphasised the importance of attending to the cultural and political factors that mediate risk communications. Sensitivity to local beliefs was particularly critical in the case of a Western scientist working in a non-Western context (a scenario familiar to many of the UK-based scientists in this sample). While lay communities' understandings were sometimes dismissed as 'nonsense', it was notable that a number of participants also described traditional beliefs about earthquakes as logical, rational, or sensible within a particular cultural context:

The traditional views are sometimes very sensible and pragmatic. They're not quantitative, they're just a sort of reasonable response to what you know [8].

These scientists thus rejected the pursuit of earthquake prediction in part for pragmatic reasons. Participants gave careful consideration to how earthquake predictions would be received by lay society, and concluded that the negative outcomes were likely to outweigh the benefits. This stance justified the field's lack of support for the empirical pursuit of prediction.

\section{Prediction is stigmatised}

While participants frequently adopted a tone dominated by logic and rationality when discussing their beliefs that prediction is impossible and harmful, another important facet of the interviews was a more emotively-infused antagonism towards the idea of predicting earthquakes. The third theme captures how participants discussed prediction in emotive terms, giving an insight into the stigmatised position that prediction occupies within earthquake science.

When asked about earthquake prediction, a common immediate response by participants was to volunteer a disclaimer that they themselves did not associate with or believe in it. These statements served the function of personally distancing the participant from prediction. One participant said:

I would say straightaway, I don't believe in earthquake prediction. . . . I don't predict earthquakes, I don't know anyone reputable that does [8]. 
Most participants openly stated that prediction was stigmatised or disparaged within the mainstream earthquake science community. The aforementioned stress on the distinction between prediction and forecasting was due in part to the negative associations attached to the term 'prediction', which was described as a 'dirty' or 'loaded' word. Participants felt that the very word 'prediction' should be avoided to ensure that their work would not be contaminated with its unfavourable connotations:

the term earthquake prediction is a very dangerous term so some people, as soon as you put the word prediction into anything on a seismic-related field some people dismiss it immediately [13].

The interviews revealed a general consensus that, owing to its stigmatised nature, engaging with prediction would have detrimental consequences for one's professional reputation and career prospects. Participants asserted that people involved in prediction research would (or should) be reluctant to admit this because of concern for their career prospects:

Well the last thing you want to do is have on your CV [curriculum vitae] that you're into earthquake prediction, because it just looks bad [10].

Individuals who did make attempts to predict earthquakes often were spoken of in disparaging terms. They were seen as, at best, misguided, and at worst, an active threat to societal well-being. Participants implied that undertaking this type of research would immediately invite questions about one's scientific credibility:

But I think anyone who said I know there is going to be an event within the year on this sort of fault, well people would think this guy is a bit of a nut and invariably the people who make those sorts of predictions are not geologists or seismologists by training . . . invariably prediction per se is made by the people who are let's say not professional, they're not a part of the broader seismological community [14].

Prediction was given the label of 'bad science' and was seen to rely on spurious correlations, post-hoc reasoning and anomalous statistics. Participants worried that prediction efforts would have a detrimental influence on their field's reputation, tainting the whole sphere with a 'bad name':

In the 70 s there was a huge effort in earthquake prediction, in the business of looking for precursory phenomena that might actually tell you in the short term whether you were going to have an earthquake or not, and to be clear it came to nothing. Not only did it come to nothing with a huge amount of money spent on it especially by the Americans but it also produced an awful lot of bad science, which rather tarnished some good science which was around but the whole subject got a rather bad name [7].

The interview with the individual who was working in the area of earthquake prediction illuminated how the stigmatised status of prediction is experienced by 
those who do engage with it. This person spent much of the interview talking about the hostility that her/his ideas had provoked among colleagues. She/he strongly believed that the controversial nature of her/his ideas had impeded the progression of her/his research and career:

My main problem is that these ideas tend to be ridiculed and violently opposed, I've got some lovely examples of violent opposition, just gorgeous! But this means that as you know research funding is usually by peer review and the peers don't like my ideas . . . because if I'm right they've been wasting their time for some while [12].

The interviews demonstrated, therefore, how the relegation of earthquake prediction was sustained by emotional and social dynamics, in addition to empirical evidence of its impossibility. Informal sanctions within the field, such as disrespect and ridicule, functioned as strong deterrents against engagement with this topic.

\section{Discussion}

In contrast to the many scientific fields for which prediction is a key guiding objective (Popper, I963; Sarewitz, Pielke, and Byerly, 2000), this study revealed the highly maligned position that earthquake prediction occupies within seismology. The analysis uncovered a very consensual representation of prediction as impossible, owing to the limits of knowledge and the inherently chaotic nature of the geological system, and as actively harmful, due to a belief that focusing on it breeds public panic and detracts attention from more worthwhile efforts to build resilience. These logicalrational appraisals of prediction's feasibility and consequences were intertwined with a more emotive representation of earthquake prediction as a 'taboo' topic within the scientific community. Prediction emerged as a highly stigmatised field that elicited strong derision from the scientists in the sample. Almost all of the participants sought to distance themselves personally from the matter and professed suspicion of those who would adopt prediction as a scientific aim. The study thus illuminates how the development and maintenance of scientific consensus is driven by emotional and social dynamics, as well as the rational appraisal of accumulating empirical evidence.

\section{The emotional and social dimensions of scientific knowledge}

Gieryn (I983) and Barnes, Bloor, and Henry (I996) argue that to maintain scientific authority, scientists routinely 'police the boundaries' between the scientific and the unscientific, attempting to stave off the intrusion of anything that may undermine its reputation. Mainstream science seeks to discredit those who threaten its credibility by associating them with quackery and poor scientific rigour, thereby delegitimising their proposals. The interviews conducted for this study provide empirical support for the pertinence of boundary work in how the issue of earthquake prediction is managed within the scientific community. A clear boundary was drawn between the 'nut' 
who pursued earthquake prediction, and the reasonable scientist who recognised the folly of this aim. This served both to marginalise the 'quack' from legitimate scientific activity, and to establish a foil in comparison to whom the mainstream scientist could demonstrate her/his own credibility. Concerned that erroneous pseudoscientific predictions would tarnish the field as a whole, scientists moved to protect their field from taint by association, by positioning prediction as decidedly beyond the boundaries of respectable science.

Corroborating the work of Ramsden (2009), this boundary work was strongly associated with stigma. Just as Ramsden (2009) noted how the negative image of eugenics led geneticists to distance themselves from it, the interviews revealed similar dynamics within the seismological community. Most participants moved to dissociate themselves personally from prediction research, aligning instead with the more scientifically respectable term of 'forecasting'. Many explicitly acknowledged the stigmatised status of prediction, observing that 'prediction' had become 'a dirty word' that one would refrain from using in scientific publications, grant and job applications, or even conversations with colleagues. In building one's professional profile, indicating an interest in prediction was strongly discouraged, due to the damage that would be incurred to one's career prospects and professional credibility.

The analysis highlighted, therefore, how the selection of scientific topics is fuelled by social dynamics within the scientific community. The stigmatisation of a scientific topic may be a self-propelling process: as it becomes a subject of disapproval, informal disciplinary sanctions (with regard to funding and job applications, for instance) confront those who engage with it, such that they lose the resources that would allow them to produce high-quality research. The association between the topic and poor-quality research is thereby consolidated further, producing a clear disincentive for scientists to move into the field. Survey research with scientists in other disciplines finds that most are very aware of the potentially controversial aspects of their work and take steps to adapt it accordingly, ranging from removing potential 'red flag' words from grant applications, dropping politically unviable research, and even changing career (Kempner, 2008). Scientific freedom to study unorthodox topics may be something of a myth: informal social dynamics may effectively prohibit people from pursuing them. This was vividly illustrated in the interview with the participant who championed prediction research and ardently opposed its relegation from mainstream science. This participant believed that she/he had devised a method that could reliably predict earthquakes, but that the contaminated status of earthquake prediction stood in the way of procuring the funding necessary to validate this approach. From this person's perspective, institutional prejudices were indeed hampering scientific progress, to the clear detriment of communities in seismicallyactive areas of the world.

The analysis thus throws light on the operations of scientific consensus and dissensus. As a social group, scientists within a field generate their own more-or-less shared representations of what they study. The interpretation of any scientific observation depends on consensual systems of classification and interpretive conventions; drawing 
meaning from a dataset depends on interpretations that have been inherited from, negotiated with, validated by, and implemented alongside others (Barnes, Bloor, and Henry, I996; Latour and Woolgar, I986). In line with the perspective of the single participant who supported earthquake prediction, overly hegemonic representations could be detrimental to the development of a scientific field if it means that minority ideas are dismissed prematurely because of stigma. Yet, boundary work and its attendant stigmatisation may fulfil important functions in the scientific process, by providing a necessary means by which scientists in a promising research area can consolidate its ascendance to legitimacy. In the case of earthquake prediction, the initial stigmatisation of the topic very likely grew out of an increasingly solid consensus that, based on the available empirical evidence, prediction was not a feasible scientific aim. With a logical basis for the rejection of prediction established, boundary work could accelerate the spread of this position throughout the field, thereby ensuring that resources are concentrated in favour of the most promising research areas. The interpenetration of logical-rational and emotional-social processes may be an important facilitator of efficient and effective scientific progress. This does not mean, however, that innovation is impossible. While not within the scope of this paper, the work of Kuhn (I962) documents how scientific revolutions take place, how the taken-for-granted flow of thinking within a field can be interrupted and a paradigm shift ensues.

The dynamic interplay of cognitive and emotive processes is well-established in psychology (see, for example, Epstein, I994; Joffe and Elsey, 20I4). This research corroborates previous studies of scientific activity (see, for example, Barnes, Bloor, and Henry, I996; Holton, I996; Latour and Woolgar, I986; Fiege, 2007) in highlighting that it is not just lay people but also scientists who operate by way of a complex intermingling of emotion and rationality. Most discussion of stigma vis-àvis scientific topics has concentrated on biases held by the general public, such as in relation to politically controversial subjects like genetically modified food (see, for example, Finucane and Holup, 2005). The results of this study show that scientists are not immune to the social dynamics that position some topics beyond the bounds of legitimacy.

\section{Science, pseudoscience, and public communication}

This study illuminates the mind set with which earthquake scientists approach the type of public communication initiatives that proved so controversial in L'Aquila. With prediction marginalised, its place in the scientific canon is filled by forecasting. Earthquake scientists distinguish forecasting from prediction by pointing to its production of probabilistic rather than categorical statements, which encompass broader margins of magnitude, space, and time. For these participants, this subtle distinction had profound implications. First, the greater margins of error involved in forecasting meant that forecasting statements had less chance of being 'wrong'. Second, while prediction was seen to undermine efforts to increase the resilience of communities 
in seismically-active areas, forecasting was seen to complement and foster initiatives to build resilience. Forecasting thus entailed less risk for the scientific community, offsetting the reputational damage that might result from 'false alarms' and mitigating the likelihood that scientific activity might trivialise the importance of building resilience.

The scientists in this study, though, feared that the prediction-forecasting distinction in which they invested such significance might be lost on members of the general public, who were represented as unable to manage cognitively issues of probability and uncertainty. This worry may indeed be vindicated in the case of the L'Aquila earthquake and its aftermath, which saw the probabilistic hazard assessments generated by the consulting scientists transformed into ever more certain terms as they were reinterpreted by public officials, the media, and lay people (Alexander, 20I4). Beyond anecdotal observation of one-off episodes such as the L'Aquila case, however, there is little empirical evidence of how lay publics construe seismic hazard assessments, their expectations of the role of scientists in forewarning society of natural hazards, and indeed their conceptualisation of prediction as a concept in and of itself. Understanding and addressing any tensions between the representations of earthquake prediction by scientists and laypeople is a clear priority in developing effective risk communication strategies.

If such science-public tensions do emerge, the findings of this paper suggest that it is important not to focus remediation measures purely on the 'public' side of the equation. Scientists concerned about the tendency for probabilistic risk statements to be transformed into categorical assertions should be careful that they do not themselves compound this propensity. In particular, attention should be paid to how mainstream science responds to episodes of pseudoscientific earthquake prediction such as those witnessed in Christchurch, L'Aquila, and Rome. The scientific community tends to see such incidents as unambiguously harmful to science and society (Dearing, I995; Smith, I996), and its response generally involves concerted efforts to discredit them. However, the antipathy with which the scientific community greets instances of prediction may result in an aggrandising of scientific risk assessments in the opposite direction; efforts to downplay the likelihood of the predicted earthquake could be construed as outright denials of earthquake risk. In other words, if mainstream science is set up in rigid opposition to 'maverick' science, public debate may polarise between the positions of 'there will be an earthquake' or 'there will not be an earthquake', and probabilistic statements that the risk is modest may be interpreted as arguments for the latter position. Scientific efforts to discredit pseudoscientific earthquake predictions may thereby have the effect of undermining public awareness of seismic risk and the mitigative or preparatory action that would follow.

A hostile opposition between mainstream and maverick science is not a necessary state of affairs. Research shows that scientific and non-scientific ways of thinking about earthquakes can coexist in lay society without major tension (Turner, Nigg, and Paz, I986; Yamori, 20I3). By entering into a direct conflict with maverick science, 
mainstream science may weaken its own support by 'forcing' people to take one side or the other. It is interesting to note that instances of prediction provoke greater awareness of seismic risk and the adoption of more preparedness behaviours, which persist even after the predicted earthquake event fails to materialise (Farley et al., I993; Showalter, I993). Hence, even if earthquake predictions are false and disconfirmed, they can succeed in inserting earthquake risk on the public agenda in a way that probabilistic risk statements cannot. Undeniably, instances of earthquake prediction can have economic, legal, and social consequences, and to allay unnecessary panic it is important to present a sober assessment of the prediction's validity. However, maverick earthquake prediction may offer an opportunity to increase awareness of the constant nature of earthquake risk. Rather than purely seeking to downplay the risk, scientific evaluations of a prediction's legitimacy could be accompanied by statements that highlight the importance of constantly maintaining preparedness for an earthquake and resilience in the face of a threat.

\section{Conclusion}

The key contribution of this study is its revelation of how earthquake scientists cognitively and emotively represent the controversial topic of earthquake prediction. For the vast majority of the scientists interviewed for this study, prediction was deemed impossible, either owing to the limits of current and foreseeable knowledge, or to the inherently chaotic nature of seismic phenomena. This was coupled with a sense that efforts towards prediction wasted money and time. Predictions were regarded as representing poor scientific rigour that, in combination with false alarms, could damage the reputation of earthquake science by provoking mass hysteria and consequent loss of life. In contrast to prediction, forecasting was seen to be worthwhile as it could aid earthquake preparation and mitigation efforts. The majority of participants explicitly distanced themselves, therefore, from earthquake prediction in favour of forecasting. Earthquake prediction was a stigmatised subject area as a result; holding an affiliation to the idea of earthquake prediction could be detrimental to career prospects. The emotional inflexion with which prediction was spoken of suggests that in scientific thought, just as in thinking among lay people, the logical- rational and emotional-social dimensions coexist. Their interaction drives scientific consensus.

\section{Acknowledgements}

The research was funded by the Engineering and Physical Sciences Research Council in the UK (grant reference: EP/FoI2I79/I). There are no known conflicts of interest. Ethical permission was obtained to conduct the interviews (University College London Ethics Project Identification (ID) Number: I392/OoI). All participants signed an informed consent form prior to interview. 


\section{Correspondence}

Helene Joffe, Department of Clinical, Educational and Health Psychology, University College London, Gower Street, London WCIE 6BT, United Kingdom.

E-mail: h.joffe@ucl.ac.uk

\section{Endnotes}

I Helene Joffe is Professor of Psychology in the Department of Clinical, Educational and Health Psychology, University College London, United Kingdom; Tiziana Rossetto is Professor of Earthquake Engineering in the Department of Civil, Environmental and Geomatic Engineering, University College London, United Kingdom; Caroline E. Bradley is Clinical Psychologist, Tavistock and Portman NHS Trust, United Kingdom; and Cliodhna O'Connor is a Lecturer in the Department of Psychology, Maynooth University, Ireland.

2 The number in brackets after a quotation is the unique, anonymous identifier of a participant.

\section{References}

Alexander, D.E. (20I4) 'Communicating earthquake risk to the public: the trial of the "L'Aquila seven"'. Natural Hazards. 72 (2). pp. II59-II73.

Allen, C.R. (1982) 'Earthquake prediction-1982 overview'. Bulletin of the Seismological Society of America. $72(6 \mathrm{~B}) \cdot \mathrm{pp} . \mathrm{S}_{33} \mathrm{I}-\mathrm{S}_{335}$.

Barnes, B., D. Bloor, and J. Henry (eds.) (1996) Scientific Knowledge: A Sociological Analysis. University of Chicago Press, Chicago, IL.

BBC (British Broadcasting Corporation) (20II) 'Rome braces for "prophet-predicted quake". BBC News. II May. http://www.bbc.com/news/world-europe-I3354988 (last accessed on Io April 20I7).

Booker, J. (20II) 'Christchurch earthquake: Ring's tip sends families fleeing'. New Zealand Herald. I9 March. http://m.nzherald.co.nz/christchurch-earthquake/news/article.cfm?c_id=I50298I \& objectid= I07I3466 (last accessed on Io April 2017).

Boyatzis, R.E. (1998) Transforming Qualitative Information: Thematic Analysis and Code Development. Sage Publishing, London.

Brace, W.F. (I975) 'The physical basis for earthquake prediction'. Technology Review. 3-4 (March-April). pp. 26-29

Brown, K.S. (1996) 'Excitement and emotion mark scientists' fleeting moments of discovery'. The Scientist. 25 November. http://www.the-scientist.com/?articles.view/articleNo/r8I86/title/ Excitement-And-Emotion-Mark-Scientists--Fleeting-Moments-Of-Discovery/ (last accessed on Io April 20I7).

Cartlidge, E. (20I5) 'Why Italian earthquake scientists were exonerated'. Science. Io February. http://www.sciencemag.org/news/2015/02/why-italian-earthquake-scientists-were-exonerated (last accessed on Io April 20I7).

Dearing, J.W. (I995) 'Newspaper coverage of maverick science: creating controversy through balancing'. Public Understanding of Science. 4(4). pp. 34I-36I.

Dearing, J.W. and J. Kazmierczak (1993) 'Making iconoclasts credible: the Iben Browning earthquake prediction'. International Journal of Mass Emergencies and Disasters. II(3). pp. 391-403.

Epstein, S. (1994) 'Integration of the cognitive and the psychodynamic unconscious'. American Psychologist. 49(8). pp. 709-724. 
Farley, J.E. (1998) Earthquake Fears, Predictions, and Preparations in Mid-America. Southern Illinois University Press, Carbondale, IL.

Farley, J.E., H.D. Barlow, M.S. Finkelstein, and L. Riley (I993) 'Earthquake hysteria, before and after: a survey and follow-up on public response to the Browning forecast'. International Journal of Mass Emergencies and Disasters. II (3). pp. 27I-277.

Feyerabend, P. (1975) Against Method: Outline of an Anarchistic Theory of Knowledge. New Left Books, London.

Fiege, M. (2007) 'The atomic scientists, the sense of wonder and the bomb'. Environmental History. I2 (3). pp. 578-6I3.

Finucane, M. and J.L. Holup (2005) 'Psychosocial and cultural factors affecting the perceived risk of genetically modified food: an overview of the literature'. Social Science and Medicine. 60(7). pp. I603-г6г2.

Fountain, H. (20II) 'Trial over earthquake in Italy puts focus on probability and panic'. The New York Times. 3 October. http://www.nytimes.com/20II/Io/o4/science/o4quake.html?_r=o (last accessed on Io April 20I7).

Friese, S. (20I4) Qualitative Data Analysis with ATLAS.ti. Second edition. Sage Publishing, London.

Geller, R.J. (I997) 'Earthquake prediction: a critical review'. Geophysical Journal International. I3 I(3). pp. $425-450$.

Geller, R.J., D.D. Jackson, Y.Y. Kagan, and F. Mulargia (I997) 'Earthquakes cannot be predicted'. Science. 275(5306). pp. I6I6-I620.

Gieryn, T.F. (I983) 'Boundary-work and the demarcation of science from non-science: strains and interests in professional ideologies of scientists'. American Sociological Review. 48(6). pp. 78I-795.

Goffman, E. (1963) Stigma: Notes on the Management of a Spoiled Identity. Prentice Hall, Englewood Cliffs, NJ.

Hall, S. (20II) 'Scientists on trial: at fault?'. Nature. 477(7364). pp. 264-269.

Holton, G. (I996) 'The role of themata in science'. Foundations of Physics. 26(4). pp. 453-465.

Hough, S. (2009) Predicting the Unpredictable: The Tumultuous Science of Earthquake Prediction. Princeton University Press, Princeton, NJ.

Howell, B.F. and C.F. Richter (I977) 'Second award of the Medal of the Seismological Society of America'. Bulletin of the Seismological Society of America. 67(4). pp. I243-I247.

Joffe, H. (2012) 'Thematic analysis'. In D. Harper and A. Thompson (eds.) Qualitative Research Methods in Mental Health and Psychotherapy: An Introduction for Students and Practitioners. Wiley-Blackwell, Chichester. pp. 209-223.

Joffe, H. and J.W.B. Elsey (2014) 'Free association in psychology and the grid elaboration method'. Review of General Psychology. I8(3). pp. I73-I85.

Kempner, J. (2008) 'The chilling effect: how do researchers react to controversy?'. PLoS Medicine. $5(\mathrm{II})$. e222.

Kevles, D.J. (1985) In the Name of Eugenics: Genetics and the Uses of Human Heredity. Harvard University Press, Boston, MA.

Kuhn, T.S. (I962) The Structure of Scientific Revolutions. First edition. University of Chicago Press, Chicago, IL.

Landis, J.R. and G.G. Koch (I977) 'The measurement of observer agreement for categorical data'. Biometrics. 33(I). pp. I59-I74.

Latour, B. and S. Woolgar (I986) Laboratory Life: The Construction of Scientific Facts. Second edition. Princeton University Press, Princeton, NJ.

Major, A.M. (I998) 'The utility of situational theory of publics for assessing public response to a disaster prediction'. Public Relations Review. 24(4). pp. 489-508.

Merton, R.K. (I975) 'Thematic analysis in science: notes on Holton's concept'. Science. I88(4I86). pp. $335-338$. 
Milne, J. (I9II) 'The observatory at Messina'. Nature. 85(2I55). pp. 5I5-5I6.

Nigg, J.M. (I982) 'Communication under conditions of uncertainty: understanding earthquake forecasting'. Journal of Communication. 32 (I). pp. 27-36.

Nosengo, N. (2010) 'Italy puts seismology in the dock'. Nature. 465 (730I). p. 992.

Popper, K.R. (I963) Conjectures and Refutations. Harper, New York, NY.

Press, F. (I975) 'Earthquake prediction'. Scientific American. $232(5)$. pp. I4-23.

Ramsden, E. (2009) 'Confronting the stigma of eugenics: genetics, demography and the problems of population'. Social Studies of Science. 39(6). pp. 853-884.

Sarewitz, D. (2010) 'World view: tomorrow never knows'. Nature. 463(7277). p. 24.

Sarewitz, D., R.A. Pielke, and R. Byerly (eds.) (200o) Prediction: Science, Decision Making, and the Future of Nature. Island Press, Washington, DC.

Shipman, M., G. Fowler, and R. Shain (I993) 'Whose fault was it?: an analysis of newspaper coverage of Iben Browning's new Madrid fault earthquake prediction'. International Journal of Mass Emergencies and Disasters. II (3). pp. 378-389.

Showalter, P.S. (I993) 'Prognostication of doom: an earthquake prediction's effect on four small communities'. International Journal of Mass Emergencies and Disasters. I I(3). pp. 279-292.

Smith, C. (I996) 'Reporters, news sources, and scientific intervention: the new Madrid earthquake prediction'. Public Understanding of Science. 5(3). pp. 205-216.

Turner, R.H., J.M. Nigg, and D.H. Paz (I986) Waiting for Disaster: Earthquake Watch in California. University of California Press, Berkeley, CA.

Wegener, A. (I929) The Origin of Continents and Oceans. Dover Publications, New York, NY.

Wilkinson, S., H. Joffe, and L. Yardley (2004) 'Qualitative data collection: interviews and focus groups'. In D.F. Marks and Y. Yardley (eds.) Research Methods for Clinical and Health Psychology. Sage Publishing, London. pp. 39-55.

Yamori, K. (2013) 'A historical overview of social representation of earthquake risk in Japan: fatalism, social reform, scientific control and collaborative risk management'. In H. Joffe, T. Rossetto, and J. Adams (eds.) Cities at Risk: Living with Peril in the 21st Century. Springer, Dordrecht. pp. 73-9I. 